\title{
Towards a Prototype of a Low-Priced Domestic Incubator with Telemetry System for Premature Babies in Lima, Peru
}

\author{
Jason Chicoma-Moreno \\ Facultad de Ciencias e Ingeniería \\ Universidad de Ciencias y Humanidades \\ Lima, Peru
}

\begin{abstract}
Complications due to preterm birth are the main factors of death in the group of children with five years of age or less. Hence, a thorough care for these babies is needed especially during the first weeks or months after birth. Because in Peru not too many families can afford to rent or buy a incubator, this work puts forward the design and construction of a low-priced domestic incubator with telemetry system. The most important parameters to monitor are considered to be: the temperature and the humidity inside of the incubator and the heart pulse of the baby. To maintain the levels of temperature and humidity according to medical standards, a software was developed in an Arduino Uno. In order that the parents monitor the aforementioned parameters not necessarily being in the same room where the incubator is, a bluetooth module was used with the Arduino Uno to transmit the data to an app installed in a mobile phone. The first tests have shown that the humidity and temperature levels within the incubator are maintained as desired, also the the heart pulse is the expected one. However, there is still some work to do in regard to the upper limits of the humidity and temperature levels, which will be implemented as the next step of the project. It is expected that this incubator will serve Peruvian families, specially those living at the edge of poverty, who do not have the possibility of affording an expensive incubator at home or paying for these services at hospitals, for their premature babies.
\end{abstract}

Keywords-Preterm babies; incubator; Arduino; telemetry

\section{INTRODUCTION}

A baby born before 37 weeks of gestation is considered premature. According to the World Health Organization [1], 15 million babies are born preterm each year. Difficulties arising from preterm birth are the number one causes of death among children aged 5 years or less. Preterm birth is divided in three subcategories according to gestational age [1]:

- Extreme preterm (less than 28 weeks)

- Very preterm (28 to 32 weeks)

- $\quad$ Moderate to late preterm (32 to 37 weeks).

As of 2014, a study [2] estimated that out of 14.8 million preterm births worldwide, 12 million of these happened in Asia and sub-Sharan Africa; nearly $81.1 \%$. The preterm birth rate in Europe, on the other hand, was estimated to be quite low; around $8.7 \%$. Among the countries that belong to the Caribbean and Latin America region, Peru was ranked in the year 2010 in the position fifteen with a preterm birth rate of $7.3 \%$ [3].
Because the organ systems of preterm babies are not well developed, special care is needed and also permanent monitoring [4]. For instance, preterm infants are affected by heat and fluid loss. Hence, in order to maintain their body temperatures within an adequate range they need to be placed in special controlled environments. Closed incubators are perfect for this task because by adjusting ambient humidity, heat and fluid evaporation can be reduced.

In Peru, many people who have premature babies do not have the enough acquisition power to buy or rent incubators, which are mostly expensive. Thus, they are only able to afford low-priced ones, but many times these are difficult to find or are not available in the market. As a consequence premature babies are likely to develop some complications which can lead to their deaths. The present work, therefore, seeks to reduce the mortality rate of premature babies in Peru. To achieve this goal, the design and construction of a low-cost domestic incubator with telemetry system for premature babies is presented. In Section II, the methodology will show both, the electronic and mechanical, parts and the developed software in charge of controlling the incubator. Section III presents the mechanical and electronic design, medical functions and results generated by the prototype of the incubator. Finally, Section IV indicates the conclusions.

\section{Methodology}

\section{A. Electronic Parts}

Because a low-priced domestic incubator is desired, the following electronic components were selected for its design and implementation:

- Arduino Uno

- $\quad$ Sensor DHT11

- $\quad$ Sen-11574

- $\quad$ Bluetooth module

- Ultrasonic humidifier

- Heating resitor

- Fans and exhaust fan

- LED indicators

- LCD screen 
- $\quad$ I2C converter

- Relay module

The Arduino Uno microcontroller board will control the reading of sensors and actuators that will be used. This will be also used for wireless communication with, for example, mobile phones and will also manage of the entire domestic incubator. DHT11 is the temperature and humidity sensor that will be used to take the measurements from the controlled environment of the incubator. Sen-11574 is the heart rate sensor; its function as implied will be to measure the heart rate of the premature baby so that it can give an early warning of any cardiac anomaly. The ultrasonic humidifier is an actuator that will serve to create the precise humidity needed inside the incubator for the premature baby. The bluetooth module will make possible the wireless communication of the microcontroller with, for example, mobile phones.

\section{B. Mechanical Materials}

Some of the most important mechanical materials that were used to build the prototype of the incubator are listed:

- Wood

- Plastic film

- Screws

- Wood sealing machine

By choosing wood and plastic film, the prototype of the baby incubator is easily portable and also quite cheap. The incubator is divided in two main areas. The area where the baby will be placed is located in the upper part of the incubator and the other one (in the lower part) is for the electronics that will be in charge of providing the right conditions for the area of the premature baby.

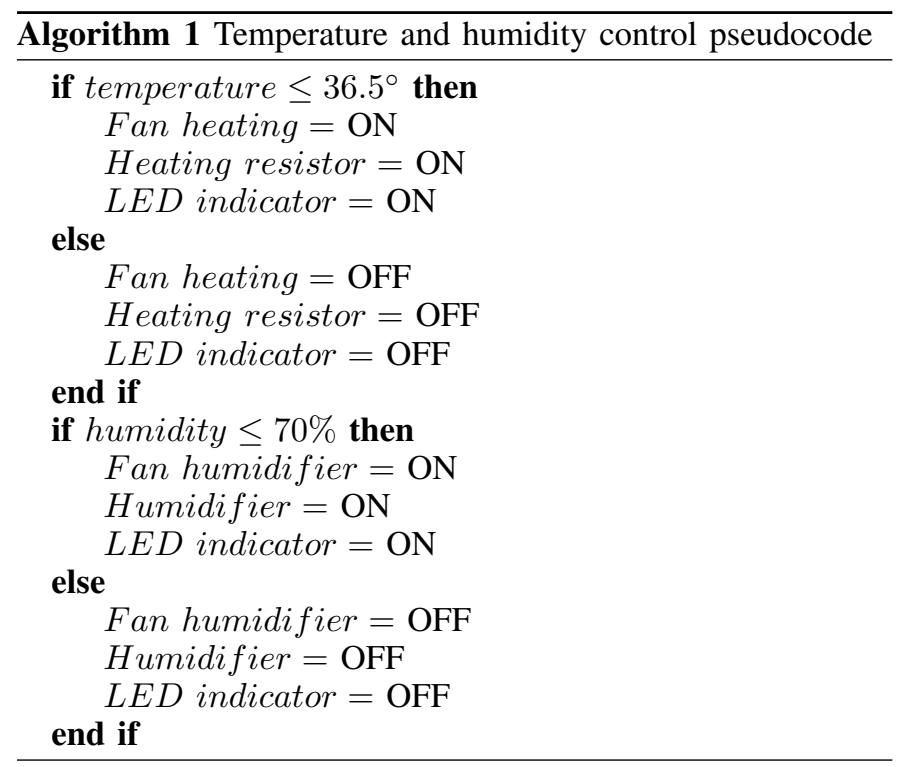

\section{Software}

The program developed in the Arduino Uno is in charge of keeping the temperature and humidity inside the incubator

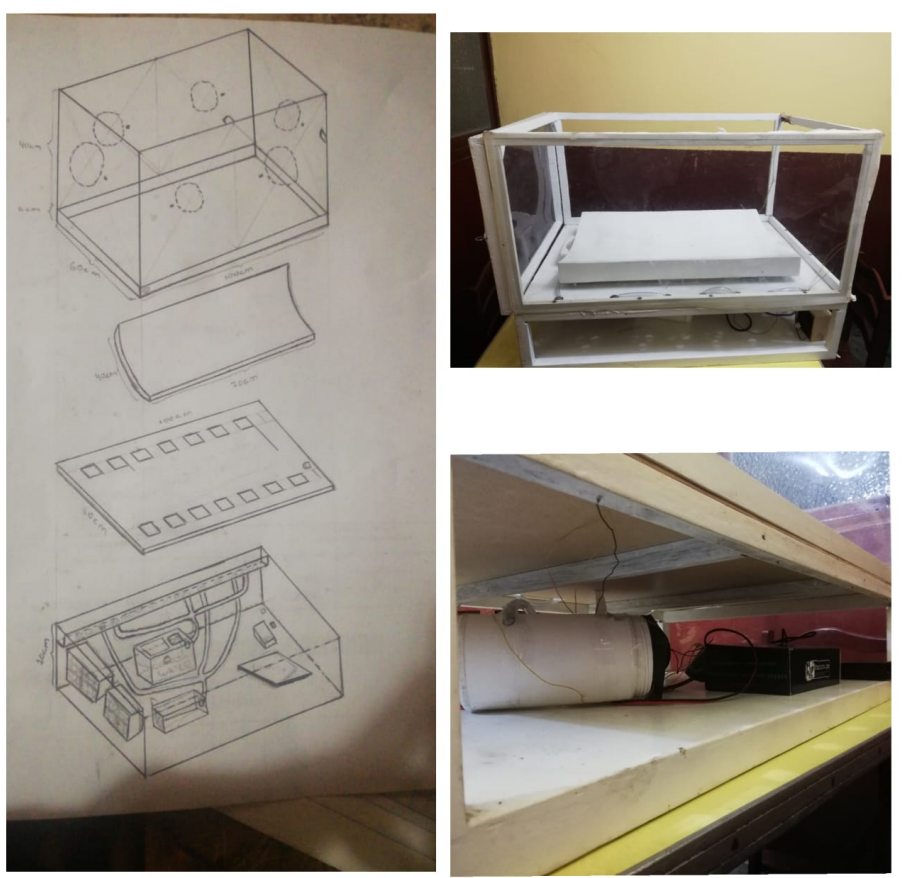

Fig. 1. Left: Schematic of thel incubator. Top Right: The incubator prototype showing the area where the premature baby lays (top) and the area of the electronics (bottom). Bottom Right: Area where the electronics are located.

according to the needs of the premature baby. The pseudocode shown in the Algorithm 1 and loaded into the Arduino demonstrates how the temperature and humidity levels are kept inside the incubator.

It is well know [5], [6], [7] that newborn temperature levels have to be kept within the range of 36.5 and $37.5^{\circ} \mathrm{C}$. Thus, the algorithm developed has to consider this upper and lower temperature limits. As shown in the Algorithm 1, the Arduino uno will turn on the heating resistor and also the fan of the heating in order to elevate the temperature of the incubator's baby area if this falls below $36.5^{\circ} \mathrm{C}$ (which is detected by the DHT11 sensor). Once this lower limit is passed, the heating resistor and its fan will turn off. The relative humidity of the area where a premature baby is located has to be maintained within the $70-75 \%$ range [8]. It can also be seen that the code developed (Algorithm 1) will turn on the ultrasonic humidifier and its respective fan once the humidity drops below $70 \%$. The fan of the humidifier will cause the water vapor to flow towards the area where the baby is located. The variation of the humidity is also detected by the DHT11 sensor. Once the humidity returns to a level above $70 \%$, the ultrasonic humidifier and its fan will turn off.

The heart rate sensor (Sen-11574) to measure the pulse is a plug-and-play one to use with the Arduino Uno. A holder was adapted for this sensor inside the incubator to use when desired. This sensor start taking measurements when it is attached to the baby's finger. The expected measured pulse has to be between 120 and 160 beats per minute (bpm) [9].

The three parameters, temperature, humidity and beats per minute, can be visualized in the LCD screen attached to one side of the incubator. The aforementioned is directly connected 


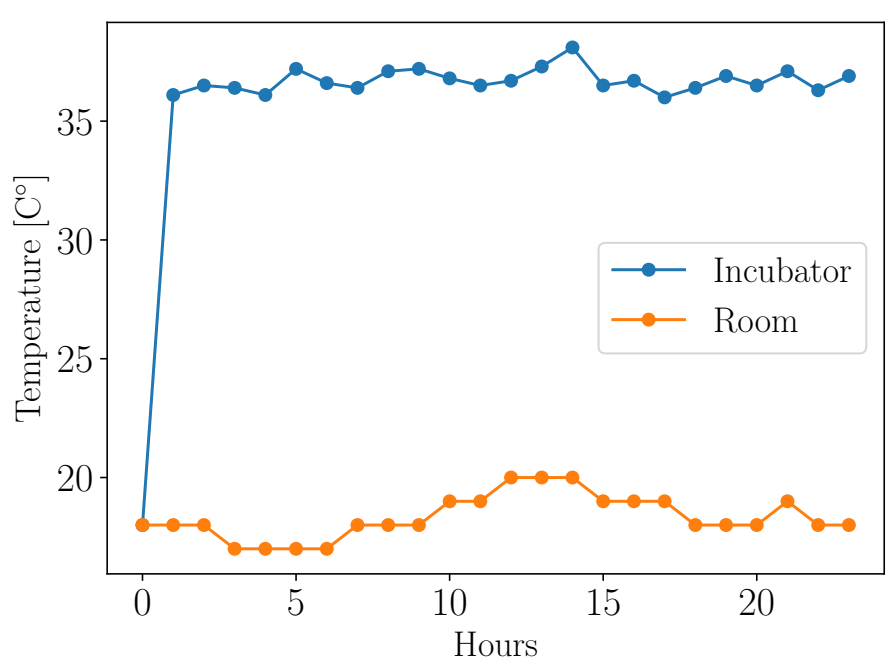

Fig. 2. Temperature monitoring over a whole day inside and outside the incubator.

to the Arduino Uno and receives and displays the data in real time.

\section{RESULTS AND DISCUSSION}

The first prototype of the mechanical part of the incubator can be seen in Fig. 1; the right upper panel. The left panel of Fig. 1 shows the schematic of the incubator. The main box at the top is where the baby be will placed. The curved plate will serve as support for the mattress where the baby will be laid. The plate with seven squared holes to the sides will serve as support and also as ventilation. The box at the bottom is where the electronics are located. Two external fans, one normal and the other an exhaust one, are in charge of keeping ventilated the electronics. The right lower panel of Fig. 1 shows a partial view of the area of the electronics.

In order to verify that the temperature system was correctly implemented, we added a new sensor DHT11 outside of the incubator and connected it to the Arduino Uno. Hence, measurements were taken over a whole day. In Fig. 2 it can be observed the measurements of both sensors, inside and outside the incubator. When the measurements initiated both temperatures were the same, that is to say at room temperature. However, once the incubator was closed, the temperature inside the incubator, in the area of the premature baby, was stabilized to the $36.5-37.5^{\circ} \mathrm{C}$ range. These tests were done during the month of April 2019, when in the capital city of Peru, Lima, usually it is autumn time, which means that it does not get really hot, more than $38^{\circ} \mathrm{C}$ for instance. If the test would have been during summer time, when in some days the temperature can be more than $38^{\circ} \mathrm{C}$, it would mean that also the temperature inside the incubator would be more that the upper accepted limit $\left(37.5^{\circ} \mathrm{C}\right)$ for the premature baby. A solution to this is the next step in the implementation of the prototype. This steps consists in adding a cooling unit. For this purpose, the use a Peltier module with its respective fan is planned. This is in order that when it gets higher than $37.5^{\circ} \mathrm{C}$ in the area of the baby the Peltier module along with is fan will turn on in order to blow cool air into the aforementioned area.

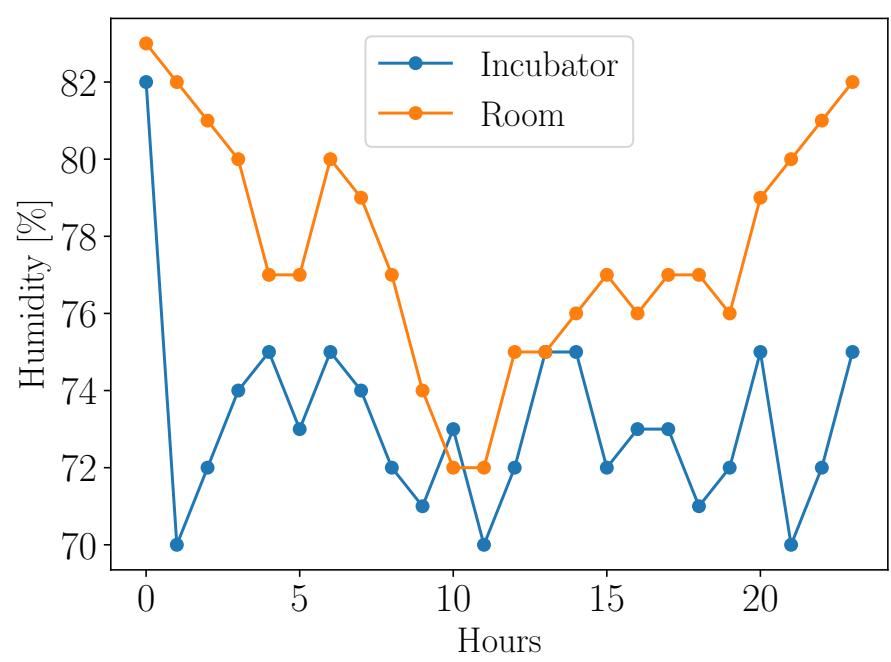

Fig. 3. Humidity monitoring over a whole day inside and outside the incubator.

If the temperature falls below this level the Peltier module and its fan are expected to turn off.

To measure the humidity as mentioned above, it is also done with the sensor DHT11. To compare again the adequate operation of this sensor along with our software, we placed a second one outside the incubator (which is the same one that measured the room temperature). In Fig. 3 the measurements of humidity levels inside and outside the incubator can be seen during a whole day. At the beginning of the measurements, the humidity levels were very similar; however, once the incubator was closed it can be seen that these stabilized within the accepted range of $70-75 \%$. Even though the exhaust fan in the area of the electronics and also also the time of the year during which the test were done has helped to reach the adequate humidity levels, this could not have been possible during summer time, where the exhaust fan alone located in the electronics area could not have done the task or reducing really high humidity levels. Therefore, as also a next step to finishing our prototype is to place an exhaust fan to remove the moisture from the area of the baby so it can reach humidity levels less than $75 \%$. As observed in Fig. 3, the humidity levels above $75 \%$ are well controlled by the ultrasonic humidifier and its respective fan.

The sensor Sen-11574 was attached to a adult male (20 yrs. old) in order to take his heart rate pulse. In Fig. 4, a sample of these measurements is observed and it is quite clear that the waveform of the pulse along with the periodicity are the expected ones.

The telemetry system is implemented via the bluetooth module hc-06 that is directly connected to the Arduino Uno. The data regarding the temperature and humidity levels and the heart rate pulse are transmitted via bluetooth from the Arduino Uno to an app installed in the mobile phone of the parents, so that they do not need to be necessarily in the same room of the incubator to monitor these parameters. 


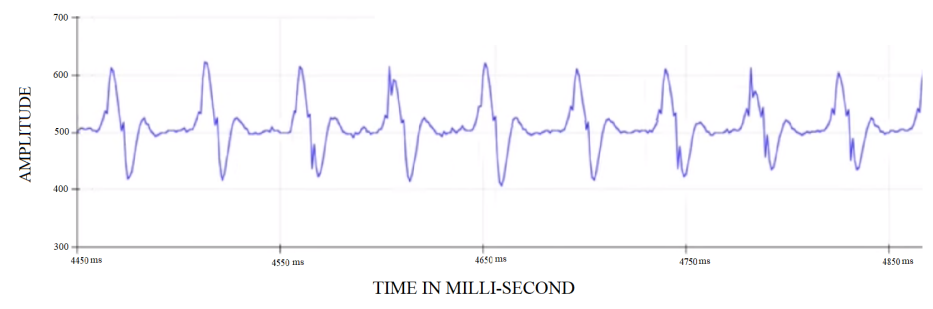

Fig. 4. Heart Rate Sample.

\section{CONCLUSIONS AND Future WORK}

The first results of the prototype of the implemented incubator for preterm babies have shown to be very encouraging. The temperature and humidity levels inside the incubators were kept between $36.5-37.5^{\circ} \mathrm{C}$ and $70-75 \%$, respectively, which are the expected ones according to medical standards. The heart pulse sensor has show to be working properly as well. Additionally, wireless communication via bluetooth was possible by using the module hc-06 and an app installed in a mobile phone.

As a future work, the incubator also has to consider what happens when the temperature inside de incubator goes beyond $37.5^{\circ} \mathrm{C}$. For this, a cooling unit based on a Peltier module is put forward. On the other hand, when the humidity level reaches $75 \%$ or more an exhaust fan in the area of the baby within the incubator is also proposed. This work is expected to serve Peruvian families, especially the ones who can not afford to rent or buy an expensive incubator at home or pay for this type of services at hospitals, with the care of their premature babies.

\section{ACKNOWLEDGMENTS}

The author is very thankful to Dr. Carlos Sotomayor Beltran for his insightful comments and helpful suggestions.

\section{REFERENCES}

[1] World Health Organization (WHO). (2018) Premature births. [Online]. Available: https://www.who.int/es/news-room/fact-sheets/detail/pretermbirth
[2] S. Chawanpaiboon, J. Vogel, A. Moller, P. Lumbiganon, M. Petzold, D. Hogan, S. Landoulsi, N. Jampathong, K. Kongwattanakul, M. Laopaiboon, C. Lewis, S. Rattanakanokchai, D. Teng, J. Thinkhamrop, K. Watananirun, J. Zhang, W. Zhou, and A. Gülmezoglu, "Global, regional, and national estimates of levels of preterm birth in 2014: a systematic review and modelling analysis," The Lancet. Global Health, vol. 7, pp. e37-e46, 2019.

[3] L. A. Mendoza Tascón, D. I. Claros Benítez, L. I. Mendoza Tascón, M. D. Arias Guatibonza, and C. B. Peñaranda Ospina, "Epidemiología de la prematuridad, sus determinantes y prevenciíon del parto prematuro," Revista chilena de obstetricia y ginecología, vol. 81, pp. 330 - 342, 2016.

[4] W. McGuire, P. McEwan, and P. Fowlie, "Care in the early newborn period," BMJ, vol. 329, pp. 1087-1089, 2004.

[5] C. A. V. D. Bosch and C. H. W. Bullough, "Effect of early suckling on term neonates' core body temperature," Annals of Tropical Paediatrics, vol. 10, no. 4, pp. 347-353, 1990.

[6] A. Singh, T. Newton, and M. Watkinson, "Improving neonatal unit admission temperatures in present babies: exothermic mattresses, polythene bags or a traditional approach?" Journal of Perinatology, vol. 30, pp. 4549, 2010.

[7] T. Tisa, Z. Nisha, and M. Kiber, "Design of an enhanced temperature control system for neonatal incubator," Bangladesh Journal of Medical Physics, vol. 5, pp. 53-61, 2013.

[8] F. Elahi and Z. A. Nisha, "Low cost neonatal incubator with smart control system," in 8th International Conference on Software, Knowledge, Information Management \& Applications (SKIMA), 122014.

[9] Stanford Children's Health. (2019) Assessments for newborn babies. [Online]. Available: https://www.stanfordchildrens.org/en/topic/default?id=assessmentsfor-newborn-babies-90-P02336 